\title{
Hepatitis B Virus DNA Can be Amplified Directly From Dried Blood Spot on Filter Paper
}

\author{
${ }^{1}$ Naglaa Fathy Alhusseini, ${ }^{1}$ Mamdouh Z. Abadeer and ${ }^{2}$ Sheref M. El-Taher \\ ${ }^{1}$ Department of Biochemistry, \\ ${ }^{2}$ Department of Community Medicine, \\ Faculty of Medicine, Benha University, Egypt
}

Received 2012-04-23, Revised 2012-05-23; Accepted 2012-06-19

\begin{abstract}
Hepatitis B Virus (HBV) infections represent a major public health problem because of the ability of HBV to cause a chronic carrier state. Even though chronic carriers remain largely asymptomatic, a large number of these individuals subsequently develop cirrhosis and primary hepatocellular carcinomas. Dried Blood Spot (DBS) samples are a simple and inexpensive sampling method, especially useful for blood collection in resource poor settings with limited access to diagnostic facilities. The main advantage of DBS samples over routine blood samples is that only a small quantity of blood, is required. They are easy to obtain, stable and can be transported to a reference laboratory at minimal cost. This study was to evaluate the feasibility of DBS samples for direct amplification of HBV DNA bypassing nucleic acid extraction. Results obtained from DBS samples were compared from those from plasma by routine molecular technique and also with those from whole blood. On the whole results for DBS, whole blood and plasma samples for HBV-DNA semi quantitative PCR monitoring, demonstrated very good agreement. This study also represents the first report in Egypt to evaluate the use of DBS to direct amplification of HBV-DNA and concluded that the use of DBS for direct amplification of HBV DNA without nucleic acid extraction was reliable, specific, sensitive, cheap and appropriate method to monitor the HBV infected patients.
\end{abstract}

Keywords: Hepatitis, HBV, DBS, Dried Blood Spot, PCR, Hepatitis B Carrier, CHB

\section{INTRODUCTION}

Hepatitis B Virus (HBV) infection is a problem in several regions of the world with limited resources Sumathi et al. (2010). (HBV) causes transient and chronic infections of the liver. Transient infections may produce serious illness and approximately $0.5 \%$ terminates with fatal, fulminate hepatitis. Chronic infections may also have serious consequences: nearly $25 \%$ terminate in untreatable liver cancer. Worldwide deaths from liver cancer caused by HBV infection probably exceed one million per year (Lira et al., 2009; Viviana et al., 2008)

The diagnosis and monitoring of HBV infection is generally based on the determination of serologic markers and viral load quantification; however, molecular characteristics such as genotype and genetic variants are not used routinely (Jardi et al., 2004).

Dried Blood Spot (DBS) can be prepared with a finger prick rather than with venipuncture, causing less discomfort to the donor. Furthermore, these samples need minimal storage space, cause little biohazard risk and are convenient for transportation. DBS have been widely used to screen genetic and metabolic disorders and to investigate polymorphisms in parasitic diseases. They are ideally suited for large-scale population screening studies, including molecular epidemiological research and blood bank procedures. For the study of Hepatitis B Virus (HBV), Dried Blood Spot (DBS) samples have been used for detecting Hepatitis $B$ virus surface antigen (HBsAg) and antibody to hepatitis B core 
antigen (Ohishi et al., 2006). Recently, DBS samples allowed the development of a simple, sensitive and appropriate test for quantifying HBV DNA and studying HBV genetic variants (Lira et al., 2009).

In spite of the urgent need for an affordable and easy sampling method for viral load testing and monitoring of chronic HBV infection, there is no report on the role of DBS in evaluation of patients infected with HBV in Egypt where the hepatitis is endemic and a very big health problem.

So this study was to evaluate the feasibility of DBS samples for direct amplification of HBV DNA bypassing nucleic acid extraction. Results obtained from DBS samples were compared from those from plasma by routine molecular technique and also with those from whole blood in blinded experiment using the same technique.

\section{MATERIALS AND METHODS}

This is a cross sectional study, included 50 hepatitis B surface antigen-positive (HBs-Ag) patients from whom attending the Molecular Biology and Biotechnology Unit, Faculty of Medicine, Benha University for monitoring of HBV markers and/or viral load, during February to September 2011. Ten HBsAg negative subjects were selected as negative controls.

\subsection{Sampling}

Three $\mathrm{mL}$ anticubital venous blood sample was collected from each subject and placed immediately into vaccutainer tube containing EDTA. Fifty $\mu \mathrm{L}$ was taken by Pastier pipette and spotted on filter paper Watman 903 for preparation of DBS. It was air dried at room temperature and then placed in plastic locked bag. One $\mathrm{mL}$ from whole blood was putted into 1.5 Eppendorf tube. The remained blood (about $2 \mathrm{~mL}$ ) was centrifuged at $3500 \mathrm{rpm}$ for plasma separation. The three form of each sample (DBS, whole blood and plasma) were stored at $-80^{\circ} \mathrm{C}$ for further processing.

\subsection{Serological assays for HBsAg, HBeAg and Anti-HBe}

The HBV serlological markers were done from plasma samples using ELISA Kit,DiaSorin S.P.A Italy, according to the manufacturer's instructions.

\subsection{Extraction of Viral DNA from Plasma Sample}

Viral DNA was extracted from each plasma sample using QIAamp Viral DNA Extraction Kit (Qiagen,
$\mathrm{GmbH}$ ) according to manufacture instructions for automatic extraction in QIAcube extractor (Qiagen, $\mathrm{GmbH})$. The extracted DNA concentration was confirmed through measurement by UV Spectrophotometer. Readings were taken at wave lengths of 260 and $280 \mathrm{~nm}$., according to that reported by (Alhusseini et al., 2011). Concentration of DNA sample

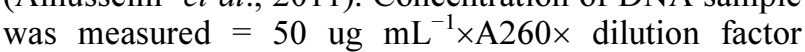
(Wilfinger et al., 1997).

\subsection{Amplification of HBV DNA by PCR}

In rapid cycler PCR (G-Storm Thermal cycler, England) $10 \mu \mathrm{L}$ from each sample of extracted DNA were used in single plex-PCR for HBV genomic DNA using PCR master mix kit (Qiagen Gmbh, Hilden, Germany) according to the manufacturer's instructions. Amplification was performed using the following primer sets provided by (Operon, inc Huntsville, Alabama Germany). Forward primer 5'TCTGCCTAATCATCTCATG-3 'reverse primer 5'GCCTCGTCGTCTAACAA-3'.

\subsection{Direct Amplification of HBV-DNA on DBS and whole Blood Without Nucleic Acid Extraction}

Using the same primers pair for $\mathrm{HBV}$, direct amplification was done for each DBS and whole blood sample using KAPA blood PCR Kit (KAPA Bio system U.S.A). The reaction mix prepared using $2.5 \mu \mathrm{L}$ EDTA blood per $25 \mu \mathrm{L}$ rxn, or $3 \mathrm{~mm}$ diameter disc from each DBS on filter paper using sterile punch. According to the manufacturer instructions the applied amplification program was $95^{\circ} \mathrm{C}$ for $5 \mathrm{~min}$. as initial denaturation then cycling for 40 cycle $\left(95^{\circ} \mathrm{C} 30 \mathrm{Sec} ., 48^{\circ} \mathrm{C} 30 \mathrm{Sec}\right.$. and $72^{\circ} \mathrm{C} 1 \mathrm{~min}$.). The final extension was $72^{\circ} \mathrm{C}$ for $2 \mathrm{~min}$.

\subsection{Post-PCR Processing and Analysis of the Amplified Products}

After completion of the PCR program the obtained amplified products were centrifuged at 14,000 rpm speed to obtain the most compact pellet of organic debris (and facilitate recovery of the ampliconcontaining supernatant.

The amplified DNA was analyzed by electrophoresis. About $10 \mu \mathrm{L}$ of each reaction mixture and 1000 Base Pair (BP) ladder (Molecular weight marker) was separated on $2 \%$ agarose gel containing $0.3 \mathrm{ug} \mathrm{mL}^{-1}$ of ethidium bromide. The bands were visualized using UV Tranilluminator $(254 \mathrm{~nm})$ and photographed using a digital camera 8 mega pixel. The image was transferred to be analyzed by computer software (Alpha In no Tech Gel Documentation System). 


\subsection{Statistical Analysis}

Statistical analysis was undertaken using SPSS computer software (SPSS Version 16 for Microsoft Windows, SPSS Inc., Chicago) and the Microsoft office Excel 2007. Quantitative data are expressed in terms of mean, standard deviation and qualitative data were expressed in number and percent, appropriate statistical tests were used (ANOVA "f" test and correlation coefficient " $r$ " test). ROC curve analysis to determine the diagnostic power of each test. Results were considered to be statistically significant at $p<0.05$.

\section{RESULTS}

To validate the utility of DBS and method of amplification of viral DNA directly in the sample without extraction, Viral Load (VL) determination of matched samples from plasma. Whole blood and DBS were performed. Viral DNA was extracted from plasma samples only and amplified as routine HBV amplification methods. All selected patients were HBsAg positive but eight of them gave undetectable results in PCR for different three samples. The clinical and virological data of the all $50 \mathrm{HBsAg}$ positive patients were described in Table (1). There is no statistical significant difference in hepatitis B viral load between the three different samples among the patients (DBS, whole blood and plasma samples) $\mathrm{p}>0.05$ Table (2). Sensitivity and specificity for DBS samples and the direct amplification method are $100 \%$ as compared to negative control samples. It also $100 \%$ as compared to other two samples Fig. (1 and 2). As regarded to differences between samples in different levels of viral load, we demonstrate that there is no statistical significant different between the three types of samples when viral loads are less than and also more than 100000 IU $\mathrm{mL}^{-1}, \mathrm{n} .=23, \mathrm{f}=0.4$ and $\mathrm{n} .=19, \mathrm{f}=1.1$ respectively $p>0.05$. The viral load amplified from DBS and whole blood samples are higher than that of plasma in case of low viremia $<100000 \mathrm{IU} \mathrm{mL}^{-1}$ Fig. (3).

Table 1. Clinical and virological patients data

\begin{tabular}{ll} 
Sex: $\delta:+\%$ & $32: 1864 \%: 36 \%$ \\
\hline Age: $/$ year Mean \pm SD (rang) & $30.58 \pm 9.57(16-54)$ \\
HBeAg +Ve & $6 / 5012 \%$ \\
AntiHBe +Ve & $4 / 508 \%$ \\
\hline
\end{tabular}

Table 2. Comparison of $\log 10$ I.U of HBV load between different samples

\begin{tabular}{llll}
\multicolumn{4}{c}{ Samples } \\
Sample type & $\log 10$ of viral load Mean \pm SD & F & P \\
\hline Plasma & n. $=42$ & & \\
Whole blood & $4.85 \pm 0.73$ & & \\
DBS & $4.66 \pm 0.67$ & 1.04 & $>0.05$ \\
\end{tabular}

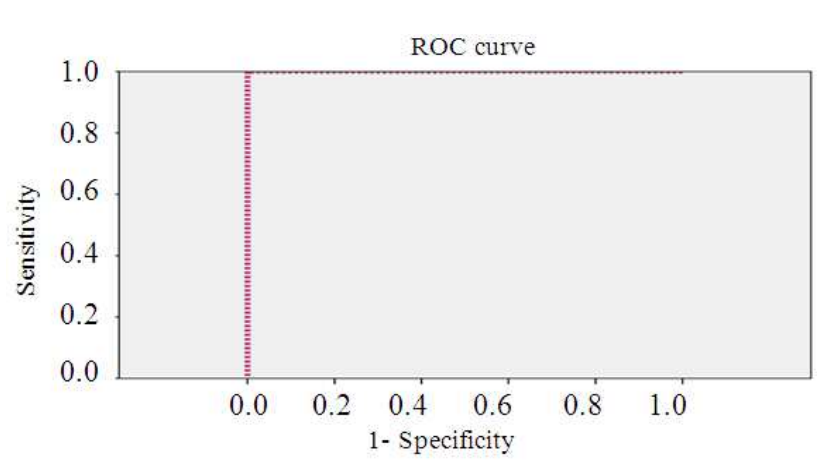

Fig. 1. ROC curve for DBS

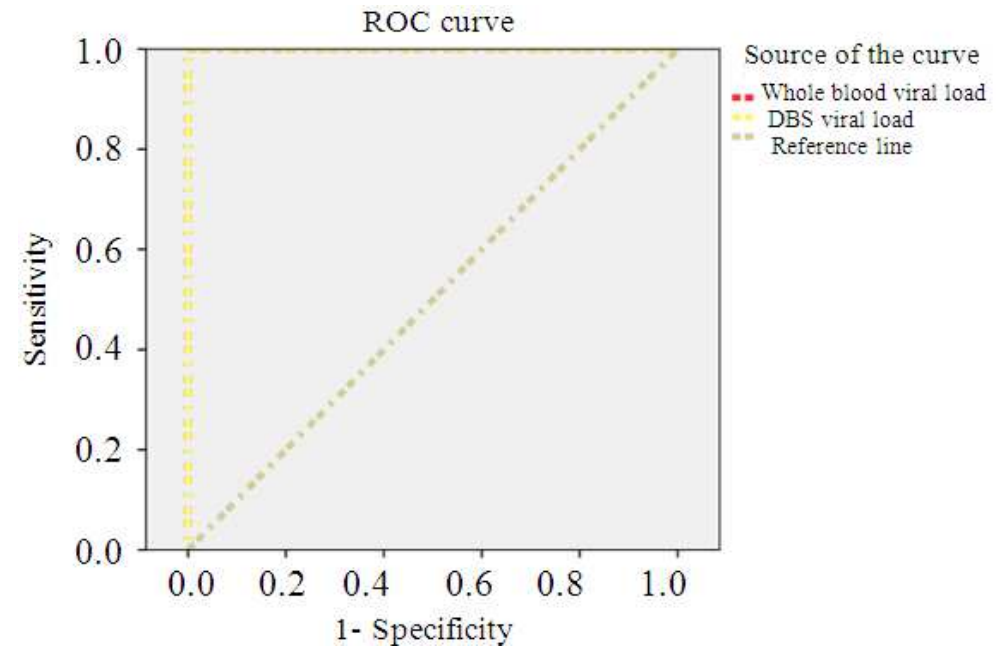

Fig. 2. ROC curve for both DBS and whole blood viral load : Area under the Curve for both viral load of whole blood and DBS is 1.000 
Naglaa Fathy Alhusseini et al. / American Journal of Biochemistry and Biotechnology 8 (2) (2012) 143-149

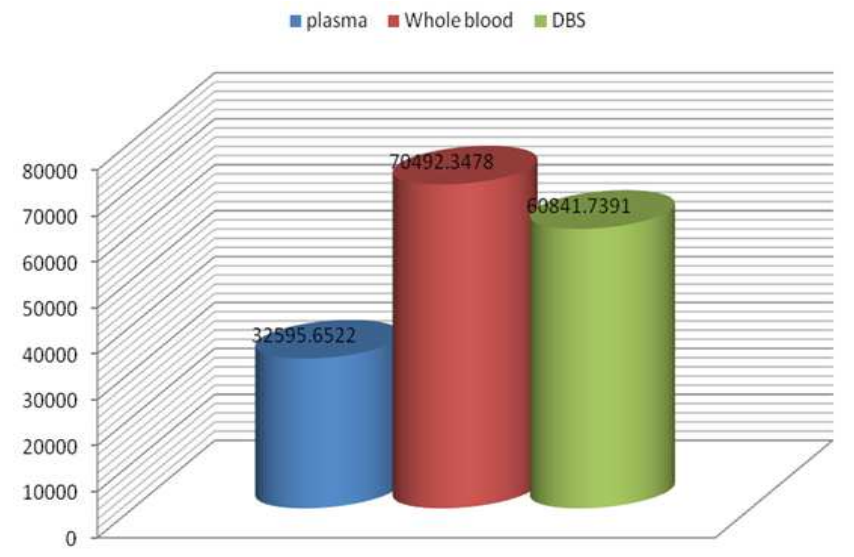

Fig. 3. Comparison between three methods when viral load is less than $100000 \mathrm{IU}$

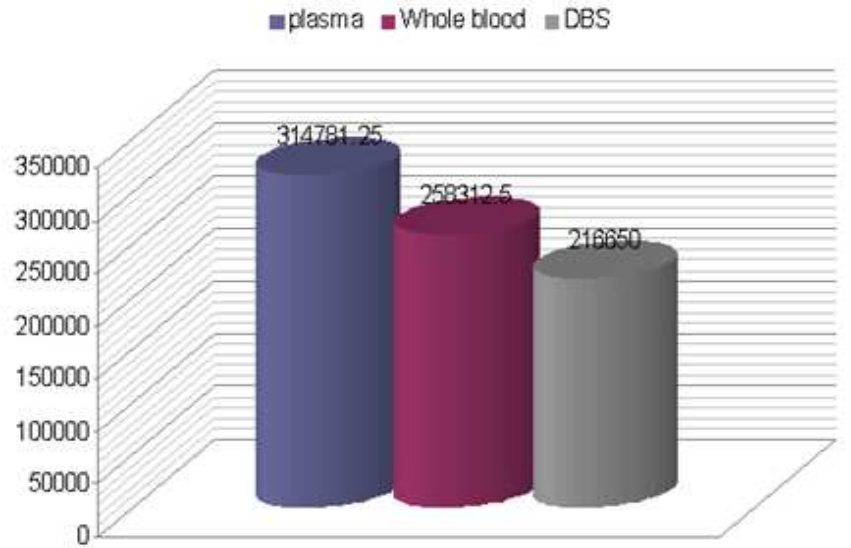

Fig. 4. Comparison between three methods when viral load is more $100000 \mathrm{IU}$
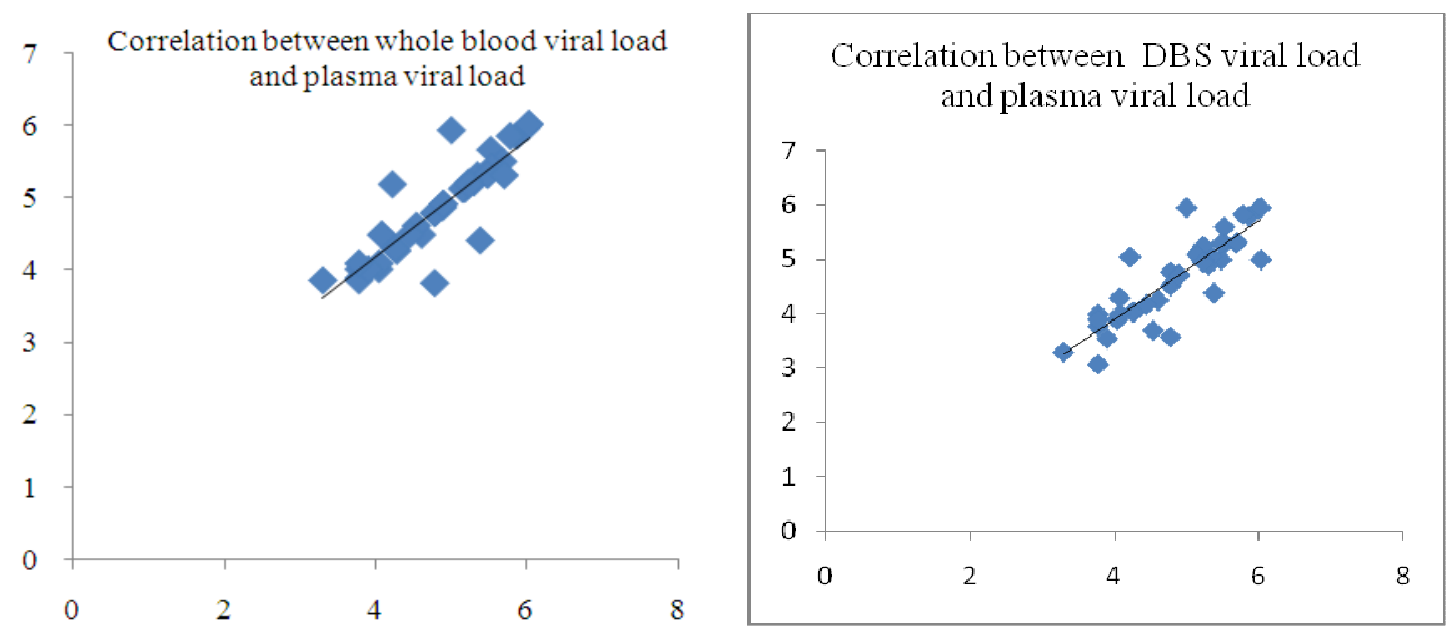

Fig. 5. Correlation coefficient "r" between viral load of whole blood, DBS and those of plasma samples 


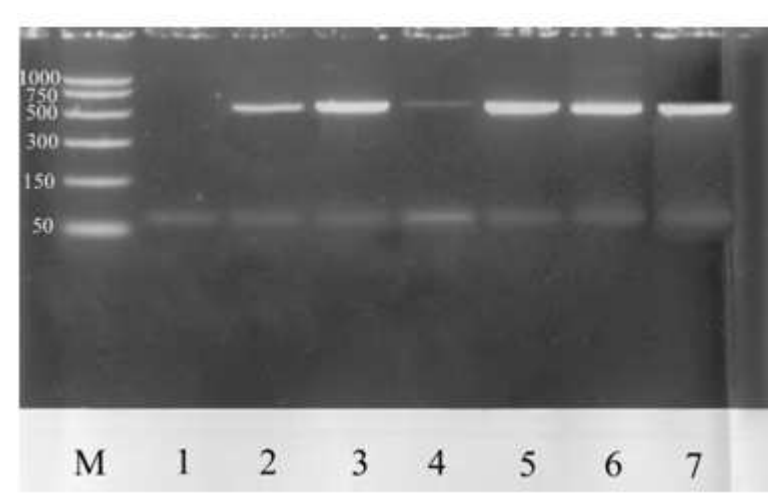

Fig. 6. Gel electrophoresis of the amplified products of HBV in different three samples, M: 1000 bp marker. Lane 1; indicate negative control. Lanes 2, 3, 4: Indicate positive for HBV with low viral load in DBS, whole blood and plasma samples correspondingly. Lanes 5, 6, 7: Indicate positive HBV with high viral load in DBS, whole blood and plasma samples correspondingly

In contrast the viral load amplified from plasma samples are higher than those of both DBS and whole blood in case of moderate and high viremia $>100000 \mathrm{IU} \mathrm{mL}^{-1}$ Fig. (4) There are significant positive correlations between viral load among plasma samples and those of DBS and whole blood samples $r=.0 .88$ and 0.86 respectively $p<0.001$ Fig. (5). The amplified products of different samples and different viral loads were uploaded on gel electrophoresis and the variation of different bands appeared as seen in (Fig 6).

\section{DISCUSSION}

Collecting capillary blood spots on filter paper requires less staff training, is less invasive, involves smaller blood volume and is ideal for high risk patients with damage veins such as intravenous drug users (Tuaillon et al., 2010). In addition this technique can reduce the cost of $\mathrm{HBV}$ testing by simplifying sample collection, processing (no centrifugation), storage and shipment. The value of DBS was for detection of HBV, HCV and HIV infection (Alter et al., 2003) and (Ohishi et al., 2006). Also other studies demonstrated the value of DBS for isolation and amplification of nucleic acid (RNA/DNA) of viral particles (Jardi et al., 2004; Tuaillon et al., 2010).

Dried Blood Spot (DBS) sampling involves the collection of whole blood samples by heel or finger-prick which is then dropped onto a filter paper, is a convenient method for obtaining and handling clinical samples intended for further analysis (Brambilla et al., 2003). This type of sampling is useful in resource-limited environments especially in the developing countries where these procedures for obtaining and handling samples for laboratory analysis could possibly reduce costs. It is a simple sampling method which requires minimal training and the risk of injuries is eliminated as needles and syringes were not used. Since DBS samples do not need special equipment for collection and transportation, costs are further reduced. This proves to be extremely advantageous for countries with limited health budgets (Lee et al., 2011).

In this study we have modified a method for the detection of HBV DNA directly on DBS by using PCR methodology. The detection of HBV DNA is traditionally carried out by PCR amplification of DNA isolation from serum/plasma (Cheyrou et al., 1991; Yokosuka et al., 1991). Since all presently available methods required serum or plasma as a starting martial,blood must be obtained by veinipuncture. In this study we successfully detect and amplify the HBV DNA by using PCR methodology directly on DBS (Gupta et al., 1992). This methods has actually bypass the veinipuncture and plasma/serum separation. Jardi et al. (2004) have assessed the DBS samples as an alternative to serum and found an important limitation of DBS. This limitation was the smaller DNA yield, that was confirmed when a significant factor where quantitative DNA analysis was concerned. They explained that may be related mainly with the dilution of the DBS samples inherent to the procedure of DBS preparation. Taylor et al. (2009) found that the precipitation methodology occurred during extraction may affect the detection level of viral load specially in cases of low viremia. In this study we overcome this limitation by bypass the extraction processing and amplify the DNA directly from DBS. A limitation that suspected to inhibit our amplification was in presence of heme in DBS which inhibit the PCR (Gupta et al., 1992). In this study we use a high fidelity 2nd generation hot start polymerase enzyme that resist inhibitors (Woolf et al., 2005).

Similar to many other studies prior to this DBS collection and processing were performed by controlled application of EDTA blood onto filter paper in laboratory conditions instead of whole blood collected directly from heel or finger-prick in a real-world situation (Uttayamakul et al., 2005; Castro et al., 2008; Kane et al., 2008; Mbida et al., 2009). Although the method of DBS collection onto the circles on the filter paper is easy and requires minimal training, the final appearances of the blood spots on the filter papers would 
still require standardization. Few studies have been conducted so far regarding the effectiveness of this DBS collection method in the field, collecting samples via infant heel-prick. Once validated, this method of blood sample collection should be able to be performed in communities in remote areas, without the need for advanced equipment, expensive transportation or shipping, maintenance of cold chain, risks associated with the handling of potentially infected material and all the costs involved (Lee et al., 2011).

\section{CONCLUSION}

This study concluded that the use of DBS for direct amplification of HBV DNA without nucleic acid extraction was reliable, specific, sensitive, cheap and appropriate method to monitor the HBV infected patients. It developed a less invasive, easy and affordable sampling method for those patients.

It presented a simple dried viable alternative for routine freezing method for transportation of clinical plasma and serum samples. This study also represents the first report in Egypt to evaluate the use of DBS to direct amplification of HBV-DNA by the second generation derived DNA polymerase using commercial kit available.

\subsection{Recommendations}

We recommended studing the use of DBS for monitoring hepatitis $\mathrm{C}$ virus infection in Egypt. Also we have to modify the amplification directly to DBS using Real time PCR.

\section{ACKNOWLEDGEMENT}

Deep and special thanks to Prof. Amal Idris, the chairman of Molecular Biology Unit, Faculty of Medicine, Benha University.

\section{REFERENCES}

Alhusseini, N.F., A.Y. Rezk, M.M. Odah, S.M.A. El Rahman and A.I. Ali, 2011. Thrombophilic genes mutations in women with repeated in-vitro fertilization failure. Am. Med. J., 2: 7-12. DOI: 10.3844 /amjsp.2011.7.12

Alter, M.J., W.L. Kuhnert and L. Finelli, 2003. Guidelines for laboratory testing and result reporting of antibody to hepatitis C virus. Centers for Disease Control and Prevention. MMWR Recomm Rep., 52: 1-13. PMID: 12585742
Brambilla, D., C. Jennings, G. Aldrovandi, J. Bremer and A.M. Comeau et al., 2003. Multicenter evaluation of use of dried blood and plasma spot specimens in quantitative assays for human immunodeficiency virus RNA: Measurement, precision, and RNA stability. J. Clin. Microbiol., 41: 888-893. DOI: 10.1128/JCM.41.5.1888-1893.2003

Castro, A.C., L.G. Borges, S. Souza Rda, M. Grudzinski and P.A. D'Azevedo, 2008. Evaluation of the human immunodeficiency virus type 1 and 2 antibodies detection in Dried whole Blood Spots (DBS) samples. Rev. Inst. Med. Trop. Sao. Paulo., 50: 151156. PMID: 18604415

Cheyrou, A., C. Guyomarc'h, P. Jasser and P. Blouin. 1991. Improved detection of HBV DNA by PCR after microwave treatment of serum. Nucl. Acids Res., 19: 4006-4006. DOI: 10.1093/nar/19.14.4006

Gupta, B.P., N. Jayasuryan and S. Jameel, 1992. Direct detection of hepatitis B virus from dried blood spots by polymerase chain reaction amplification. J. Clin. Microbiol., 30: 1913-1916. PMID: 1500493

Jardi, R., F. Rodriguez, M. Buti, M. Schaper and A. Valdes et al., 2004. Usefulness of dried blood samples for quantification and molecular characterization of HBV-DNA. Hepatology, 40: 133-139. DOI: 10.1002/hep.20275

Kane, C.T., H.D. Ndiaye, S. Diallo, I. Ndiaye and A.S. Wade et al., 2008. Quantitation of HIV-1 RNA in dried blood spots by the real-time NucliSENS EasyQ HIV-1 assay in Senegal. J. Virol. Methods, 148: 291-295. PMID: 18242718

Lee, C.E., S.S. Ponnampalavanar, S.F.S. Omar, S. Mahadeva and L.Y. Ong et al., 2011. Evaluation of the dried blood spot (DBS) collection method as a tool for detection of $\mathrm{HIV} \mathrm{Ag/Ab,} \mathrm{HBsAg,} \mathrm{anti-HBs}$ and anti-HCV in a Malaysian tertiary referral hospital. Ann. Acad Med. Singapore, 40: 448-53. PMID: 22206053

Lira, R., A. Maldonado-Rodriguez, O. Rojas-Montes, M. Ruiz-Tachiquin and R. Torres-Ibarra et al., 2009. Use of dried blood samples for monitoring hepatitis B virus infection. Virol. J., 6: 153-153. DOI: 10.1186/1743-422X-6-153

Mbida, A.D., S. Sosso, P. Flori, H. Saoudin and P. Lawrence et al., 2009. Measure of viral load by using the Abbott Real-Time HIV-1 assay on dried blood and plasma spot specimens collected in 2 rural dispensaries in Cameroon. J Acquir Immune Defic. Syndr., 52: 9-16. PMID: 19620878 
Ohishi, W., S. Fujiwara, G. Suzuki, T. Kishi and M. Sora et al., 2006. Feasibility of freeze-dried sera for serological and molecular biological detection of hepatitis B and C viruses. J. Clin. Microbiol., 44: 4593-4595. DOI: 10.1128/JCM.00621-06

Sumathi, M., M. Bala, R.K. Jain, M. Malhotra and K. Ray, 2010. Hepatitis $B$ and $C$ positivity in various categories of human immunodeficiency virus seropositive individuals in a regional STD centre-an eight-year evaluation of trends and risk factors. Am. Med. J., 1: 103-108. DOI: 10.3844/amjsp.2009.103.108

Tuaillon, E., A.M. Mondian, F. Meroueh, L. Ottomani and M.C. Picot et al., 2010. Dried blood spot for hepatitis $\mathrm{C}$ virus serology and molecular testing. Heparology, 51: 752-758. DOI: 10.1002/hep.23407

Taylor, D.O., J. Stehlik, L.B. Edwards, P. Aurora and J. D. Christie et al., 2009. Registry of the international society for heart and lung transplantation: Twentysixth official adult heart transplant report-2009. J. Heart Lung Transplant., 28: 1007-1022. DOI:10.1016/j.healun.2009.08.014

Uttayamakul, S., S. Likanonsakul, R. Sunthornkachit, K. Kuntiranont and S. Louisirirotchanakul et al., 2005. Usage of dried blood spots for molecular diagnosis and monitoring HIV-1 infection. J. Virol. Methods, 128: 128-34. PMID: 15913797
Wilfinger, W.W., K. Mackey and P. Chomczynskip, 1997. Effect of $\mathrm{pH}$ and ionic strength on the spectrophotometric assessment of nucleic acid purity. Biotechniques, 22: 474-176. PMID: 9067025

Viviana, F., I. Menendez, N. Acosta-Rivero, M. Shibayama and M.C.D. Rosa et al., 2008. Ultra structural evidences of hepatitis B infection in human liver biopsies disclose complex assembly and morphogenesis pathways for hepatitis B virus. Am. J. Infect. Dis., 4: 96-103. DOI: 10.3844/ajidsp.2008.96.103

Woolf, A., M. Goodson, D.K. Goode, P. Snell and G.K. McEwen et al., 2004. Highly conserved non-coding sequences are associated with vertebrate development. PLoS Biol., 3: e7. DOI: 10.1371/journal.pbio.0030007

Yokosuka, O., M. Omata, K. Hosoda, M. Tada and T. Ehata et al., 1991. Detection and direct sequencing of hepatitis B virus genome by DNA amplification method. Gastroenterology, 100: 175-181. PMID: 1983819 